\title{
POPULISMO, COGNITIVISMO Y CRÍTICA DE LA RAZÓN
}

\author{
Populism, Cognitivism, and the Critique of Reason
}

\author{
Alessandro Caviglia \\ Pontificia Universidad Católica del Perú, Perú \\ https://:orcid.org/0000-0002-8106-7201 \\ ascaviglia@yahoo.com
}

\begin{abstract}
RESUMEN
El presente trabajo busca ofrecer una aproximación filosófica al fenómeno del populismo, enfoque que difiere del que proviene de las ciencias sociales por que ofrece aspectos críticos y normativos. En ese sentido se criticará el anticognitivismo y el dogmatismo de las propuestas populistas y se contrapondrá el ideal kantiano del Reino de fines al concepto sustantivado de pueblo ofrecido por teóricos del populismo como Ernesto Laclau.
\end{abstract}

\section{Palabras clave:}

Populismo, antocognitivismo, dogmatismo, ciencias políticas, metafísica populista

\begin{abstract}
The present work seeks to offer a philosophical approach to the phenomenon of populism, an approach that differs from the one that comes from the social sciences because it offers critical and normative aspects. In this sense, the anticognitivism and dogmatism of the populist proposals will be criticized and the Kantian ideal of the Kingdom of ends will be opposed to the substantive concept of the people offered by populist theorists such as Ernesto Laclau.
\end{abstract}

\section{Keywords}

Populism, anticognitivism, dogmatism, political science, populist metaphysics 
El populismo es un fenómeno político que tiene gran presencia en la escena política y social contemporáneas que es estudiado desde diferentes disciplinas, especialmente, la ciencia política. Muchos de los estudios sobre el populismo han tenido un enfoque empírico y hermenéutico, siendo escasos los estudios que tienen una perspectiva normativa y crítica. Este abordaje muestra claramente sus deficiencias porque se limitan a describir el fenómeno y a buscar comprenderlo, dejando fuera la perspectiva crítica. Hay quienes señalan que la comprensión y la crítica de un fenómeno son dos momentos consecutivos y que no se puede criticar algo que no se ha comprendido previamente, pero esta mirada se encuentra desencaminada. Más bien, la hermenéutica y la crítica son dos aproximaciones alternativas a los fenómenos, y no se pueden colocar uno detrás del otro en una supuesta operación argumentativa compleja (Habermas, 2009, pp. 173-254). En el presente trabajo abordaremos la cuestión del populismo desde un enfoque normativista que tiene una significativa carga cognitivista, a fin de tener una mirada crítica del fenómeno.

La operación populista, que consiste en apelar al «pueblo» definido por medio de «significantes flotantes o vacío» por medio de una aproximación ideacional, que toma distancia de toda «ideología densa», como podría ser el socialismo (Cas, 2017, pp. 45-46; Laclau, 2020, p 136, 163), termina volviendo a la política carente de contenido cognitivo y apelando a un supuesto «residuo irracional irreductible». El resultado de tal jugada es que el debate público queda eliminado y es reemplazado por la fuerza. En este sentido, veremos que la crítica de Platón a la democracia (por su vacío cognitivo) es aplicable al populismo (1). Al mismo tiempo, constataremos cómo el populismo se encuentra cargado de una «metafísica densa» que hereda de la teología política de Carl Schmitt, la cual debe ser sometida a crítica (2). Seguidamente apuntaremos la manera en la que dicha metafísica densa tiene una serie de presupuestos teóricos que es necesario cuestionar, para mostrar la manera en la que el discurso populista es altamente dogmático (3). Finalmente, extraeremos las conclusiones que se derivan para la política de esta crítica del populismo (4).

\section{La crítica del anticognitivismo populista}

Uno de los aspectos de la crítica de Platón a la democracia consiste en que en ella el pueblo deviene en una masa amorfa donde las razones han quedado desplazadas por los intereses y deseos al momento de pensar la constitución política de la ciudad. En esta situación, cada individuo atomizado se siente con el derecho de afirmar su soberanía sin entablar un intercambio de razones con los demás. Este ataque al cognitivismo, que se encuentra en la democracia que Platón describe, llama su atención profundamente. Este ataque contra el cognitivismo lo presenta el filósofo griego como el ataque de los deseos contra la razón en un alma que "no da acogida a máxima alguna de verdad ni deja entrar en su reducto si alguien le dice que son distintos los placeres que traen los deseos justos y dignos y los que responden a los deseos perversos" (Platón, 2001, pp. 561 b-c). Para él, no resulta extraño que ese tipo de democracia desemboque en la figura de la tiranía, en la cual uno de los individuos consigue imponer a todos los demás sus deseos e intereses particulares (Platón, 2001, 571a, 573a-b). No es raro, para el filósofo ateniense, que el resultado final de la figura termine siendo el dominio 
arbitrario de un individuo, ya que el tejido político de la misma democracia se encuentra confeccionado por la suma de las arbitrariedades individuales ${ }^{1}$ (SanchoRocher, 2001, pp. 104-108).

En esta situación predomina el anticognitivismo que se caracteriza por el rechazo del intercambio de razones. Antes de seguir adelante es necesario aclarar los términos «cognitivismo práctico» y «razones». El primero refiere a que, en los terrenos normativos, como la moral, la política y el derecho, los elementos cognitivos tienen un peso decisorio. Aunque no se trata de los únicos elementos que se entran en juego, son los más relevantes y los que deberían imprimir la dirección a las acciones y ubicarse en el centro de los sistemas normativos. Dichos elementos permiten mantener a raya la arbitrariedad y, en política, el uso arbitrario del poder (Forst, 2014 , p. 19). Ahora bien, existen tres formas de entender los elementos cognitivos (también llamados «cogniciones»). La primera entiende que toda cognición es un contenido mental, de tal manera que los sentimientos, los deseos y los conceptos son cogniciones). La segunda forma señala que las cogniciones son razones para actuar, donde el término «razones» puede ser intercambiado por «motivos de cualquier índole». De esta forma, las emociones pueden ser «razones» fundamentales para la acción política. Esta segunda comprensión del término «cognición» comparte con la primera el que abarca tanto los sentimientos, los deseos, las emociones y los conceptos. Además, señala que estas razones se encuentran interconectadas en un sistema holista de creencias. La tercera concepción de lo cognitivo señala que sólo los conceptos son elementos cognitivos relevantes, con lo cual se desplaza a un segundo plano los deseos, los sentimientos y las emociones (Brandom, 2005, p. 37 ss.).

Los defensores de las primeros dos maneras de definir lo cognitivo señalan que la tercera forma es muy reductiva y que excluye elementos importantes y significativos. Quienes apostamos por la tercera forma de entender lo cognitivo es que centrarse en los conceptos permite tener un enfoque basado en los juicios, entendidos como elementos centrales del pensar y el actuar humanos. La centralidad de los juicios permite la reflexividad suficientemente consiente para poder entender la manera en que las cogniciones son normativas (ya que tener un juicio implica contar con una regla para su aplicación). Además, los juicios se articulan en inferencias que se exponen a todos para que toda persona pueda evaluar si en ellas los juicios se encuentran encadenados unos a otros de manera correcta (es decir, conforme lo indican las reglas que los dominan). Al encontrase expuestas a todos, los razonamientos inferenciales pueden ser evaluados, criticados y fundamentados, ya que se insertan en el espacio de las razones (Brandom, 2005, pp. 38, 41 ss). Con esto se consigue algo que los primeros dos enfoques no permiten: las personas no pueden recurrir a elementos que se encuentran extraídos del enjuiciamiento para neutralizar la crítica. Al dotar de un mayor peso a las emociones y sentimientos, los dos primeros enfoques defienden que hay elementos cognitivos valiosos que se encuentran por fuera del enjuiciamiento crítico de todos, los cuales sólo se podrían comprender y criticar «desde dentro de los lenguajes comunitarios». Con ello, los dos primeros enfoques terminan realizando una jugada

1 Estoy en deuda con Ronald Reyes respecto de esta lectura del populismo desde Platón. 
hermenéutica que termina defendiendo la inconmensurabilidad de los lenguajes y la impermeabilidad de las culturas, lo que resulta ser un coqueteo el funcionalismo cultural de los años 60.

En populismo sostiene que existe un componente irracional en la política que es irreductible, componente que es anticognitivista, y el asunto se pierde en el psicoanálisis lacaniano una vez que entramos en el terreno de "la Cosa perdida [que] no es una imposibilidad del pensamiento, sino un vacío del Ser" (Laclau, 2020, p. 145). Pero también es cierto que puede nutrirse de unas dos primeras concepciones del cognitivismo, ya que estas cierran el intercambio de razones en elementos que no son razones y que se constituyen como elementos metafísicos (como las emociones, los sentimientos o las tradiciones culturales y religiosas que se «desmarcan» del dar y recibir razones. En esto, el populismo se convierte en una propuesta antinormativista. El normativismo se funda en la posibilidad de dotar de exigencias basadas en razones tanto a las normas prácticas como a las acciones. Es en ese sentido que para el normativismo en intercambio y el examen de razones son elementos centrales. Razones que son opacas y poco trasparentes no sirven para dotar de justificación, ya que no pueden ingresar al espacio de las razones de manera adecuada. El populismo tiene una normatividad endeble porque se centra en razones que puedan encontrar una validez omnilateral.

\section{Populista y metafísica}

Como hemos visto, en la perspectiva de Platón, el resultado del régimen democrático no es la tiranía. El mismo diagnóstico es el que tendrá Carl Schmitt, para quien la dictadura comisarial en el resultado natural de la democracia (Schmitt, 2003, pp. 186-192). Pero, a diferencia de Platón, Schmitt ve en ello un proceso positivo, ya que el pueblo necesita alguien que se encuentre por encima del derecho para dirigirlo adecuadamente. Además, al entender de "todos los conceptos significativos de la moderna teoría del Estado son conceptos teológicos secularizados" (Schmitt, 2004b, p. 43) el jurista alemán termina cargando de una metafísica densa a las relaciones políticas y jurídicas (Arato, 2013, pp. 144-145).

Esta operación es utilizada subrepticiamente por los teóricos populistas quienes recurren a una «metafísica de pueblo» que contiene, además, atributos morales. Para ellos el pueblo en una entidad metafísica (carente de diferenciaciones internas) a la vez de tener el atributo moral de la pureza (en contraste de una élite, socialdemócrata o neoliberal, que es moralmente corrupta). La concepción metafísica del pueblo puro incluye el rechazo de la constitución de sociedades multiculturales por medio de políticas de migración externa, políticas atribuidas a la élite corrupta. Como consecuencia de esta metafísica del pueblo, se produce una distinción entre puro e impuro que empata con la concepción schmittiana de la política definida como contraposición entre amigo y enemigo (Schmitt, 2004a, p. 177). Para el populismo, el enemigo es impuro y se encarna en dos grupos específicos: la élite (definida como corrupta) y el inmigrante (definido como abyecto). En por ello que los líderes populistas cultivan y promueven la xenofobia frente al extranjero. Esta «contradistinción» populista introduce un elemento sacral que Weber había estudiado perfectamente, a saber, la idea del calvinismo primitivo de la creación del Reino de Dios en esta tierra por medio 
de la política radical (Weber, 2011, pp. 351-355).

La metafísica del pueblo no sólo emprende un ataque contra los «enemigos del pueblo» sino también en contra de la diversidad de este. Es por ello que el populismo se mueve entre la ignorancia de la sociedad civil y el ataque de la misma (Laclau, 2020, pp. 122-131). La ignorancia se debe a que considera que la relación política es directa, sin mediaciones y es entre el pueblo, el líder y el acontecimiento político irruptivo (Rovira Kaltwasser, 2019, p. 26). El ataque a la sociedad civil es porque ésta es entendida como un elemento que se encuentra en manos de la élite corrupta, que defiende la pluralidad, que se encuentra institucionalizada y que canaliza los asuntos políticos por vías regulares, mediatizando la actividad política. Al igual que busca desestructurar las instituciones jurídicas y políticas en nombre de (una verdadera democracia» también busca transformar a una sociedad civil diversa - que tiene en su base el intercambio de razones - en un pueblo uniforme, que tiene como eje central al enemigo.

Esta actitud tiene su origen en la comprensión gramsciana de la sociedad civil como el espacio por el que circula la ideología de la élite dominante. Así, las instituciones de la sociedad civil (universidades, clubes, colegios profesionales, iglesias, ONGs., la prensa) en cambio de generar opinión pública, lo que harían es fortalecer la ideología que permite a la élite corrupta (Cas $\varepsilon$ Rovira Kaltwasser, 2019, pp. 41-47) capturar la conciencia del pueblo. En este contexto, los líderes populistas son los que introducen la levadura para que fermente la masa de pan en parte del pueblo. Con ello generan una distinción entre pueblo auténtico y el falso pueblo.
Mientras que el auténtico pueblo sigue al líder populista, el falso se encontraría capturado por el discurso de la élite. En este sentido, los populistas encuentran que parte de la política consiste en una lucha de discursos, para ver cuál de ellos logra prevalecer. En vez de entender el discurso como un elemento orientado al entendimiento, sostienen una concepción agonal del mismo. La sociedad deviene, entonces, en el terreno en el que el pueblo se enfrenta a sus enemigos para que su discurso prevalezca. Entonces la dinámica discursiva deviene en una confrontación donde el contenido del discurso no cuenta.

\section{Crítica de la metafísica populista}

Los teóricos populistas tienen una concepción metafísica de la actividad política. Esta se hace patente cuando recurren a una reificación del «pueblo», pero también se encuentra presente en su concepción de «poder constituyente» o de «soberanía». Todos esos conceptos metafísicos dan al pensamiento populista una contextura dogmática. En su Crítica de la razón pura Immanuel Kant señala acertadamente que el dogmatismo conduce a la crisis de la metafísica (es decir, de la filosofía) (KrV, AA, 05: AVII-AIX) y el único camino que permite salir de ésta es por medio de la crítica (KrV, AA, 05: AXIIAXIV). Esto que el filósofo de la Ilustración indica respecto de la metafísica tiene su correlato en los «asuntos prácticos», vinculados a la libertad. Así, en la moral, el derecho o la política se pueden instalar pensamientos dogmáticos que conducen a la crisis y que requieren el ejercicio de la crítica. De esta manera, el advenimiento del populismo no es la solución a la crisis política (como, por ejemplo, la crisis de representación) -como sostienen los defensores del pensamiento populista-, 
sino una de sus causas o un síntoma de esta.

En el prólogo a la primera edición de la Crítica de la razón pura Kant figura con claridad la situación de la filosofía. Ésta se encuentra plagada de posiciones metafísicas de carácter dogmático (KrV, AA, 05: AXII-AXIV). La metafísica dogmática es aquella que afirma tener conocimiento de objetos que se encuentran más allá de los límites de la experiencia, como son el alma humana, Dios, el mundo, etc. Como con esto se sobrepasa la capacidad que tiene la razón, no hay forma de llegar un acuerdo sobre esos supuestos conocimientos. Esto conduce que diferentes posiciones metafísicas afirmen sus propios objetos sin poder exponer claramente las razones en las que se sustentan. Con ello, el terreno de la metafísica deviene en el de la arbitrariedad que Kant denomina campo de batalla. La guerra civil en la metafísica sólo se puede superar por medio de la «crítica». La operación que la crítica lleva a cabo es la de separar con claridad aquello que se puede conocer de aquello que no. Sólo es posible conocer aquello que se encuentra en la experiencia. En cambio, todo lo que la sobrepasa, no está al alcance del conocimiento humano. De tal manera, objetos metafísicos no están a nuestro alcance.

La estrategia argumentativa de Kant no se limita a eso, sino que da dos pasos adicionales. El primero es especificar cómo opera el entendimiento para producir el conocimiento de los fenómenos (es decir, los objetos de nuestro conocimiento). El segundo paso consiste en establecer la distinción entre el uso teórico y el uso práctico de la razón. Kant no sólo se encarga limitar el conocimiento, sino que lleva adelante una investigación a fin de aclarar qué implica tener «conocimiento legítimo». Tal investigación arroja como resultado la distinción entre «fenómeno» y «cosa en sí».

Los objetos del conocimiento no son las cosas en sí mismas, sino los fenómenos. Éstos son fruto de la elaboración que hace el entendimiento por medio de los enlaces que son las categorías. Éstas son elementos basados en juicios que permiten articular el conocimiento, que opera por medio de conceptos. La aplicación de conceptos tiene en sí misma su pauta de corrección, de manera que en ello de juega una exigencia normativa. En otras palabras, tener un concepto implica tener una regla de la aplicación del mismo, de tal manera que cualquiera puede evaluar si éste ha sido correctamente aplicado. De allí surge la exigencia normativa del entendimiento. Ahora bien, los conceptos se articulan en juicios que permiten establecer el carácter inferencial del pensamiento. Todo ello tiene la suficiente transparencia para que nuestros juicios e inferencias puedan ser examinadas por las demás personas y, de ser en caso, corregidas. En todo ello no hay nada oscuro, mágico o correspondiente a alguna inspiración o poder especial que sólo una élite tiene. Quien apele a elementos de tal naturaleza serán desenmascarados como farsantes.

Al delimitar el campo del conocimiento, Kant establece la distinción entre el uso teórico y el uso práctico de la razón. Mientras que el primero restringe los límites del conocimiento a los fenómenos, el segundo permite «pensar» ideas prácticas, las cuales completan las aspiraciones de la razón y abren el campo a la producción de los principios para la acción. Una de las ideas centrales es la de libertad, la cual es el fundamento de la moral autónomo. Con ello Kant abre paso 
al «principio supremo de la moralidad». Lo importante para nuestro objetivo es que la razón práctica articula todo campo normativo para la acción (moral, jurídico y político) de manera que éstos no se fundan en objetos metafísicos que serían supuestos objetos de conocimiento de la razón teórica. De tal manera, cosas como la libertad, la universidad, la sociedad civil o el pueblo son ideas de la razón que no implican conocimiento alguno, sino que operan como postulados necesarios para la práctica.

La crítica de la razón populista opera, entonces, desenmascarando sus pretensiones de tener un conocimiento teórico de un objeto metafísico que sería «el pueblo puro». Esta crítica se abre paso denunciando el dogmatismo presente en ello y señalando que con pseudoconocimientos como esos no se puede ir muy lejos en el terreno político. Esto es así, porque con tales objetos metafísicos se cancela todo intercambio de razones. Dicho de otra forma, «el pueblo» puede ser tomado en dos sentidos: como objeto de un supuesto conocimiento metafísico o como una idea práctica. Si se toda en el primer sentido, se extrae del campo de las razones, en cambio, si se le toma como una idea práctica se inserta en la dinámica del intercambio de razones. El pueblo como objeto metafísico es algo que debe ser aceptado sin cuestionamiento o impuesto por la fuerza. En cambio, si es tomado como una idea de la razón práctica se presenta como en foco del intercambio de razones de la pluralidad de participantes. De hecho, para Kant, la idea del pueblo no es otra que la idea del Reino de fines, donde lo que se encuentra en el centro es el intercambio de razones.
A la luz de las ideas de Schmitt, teóricos populistas como Ernesto Laclau no hacen más que substancializar lo que no es más que una idea de la razón. Al hacer eso, introducen necesariamente la consecuencia que Platón ya había revisto, a saber, la de la tiranía y la dominación. La apelación a la centralidad del supuesto elemento irracional inherente a la política conduce no a otro foso que al de la arbitrariedad del líder que termina supuestamente encarnando la soberanía popular. Dicha arbitrariedad expulsa las razones de la política y las reemplaza por el uso de la fuerza que apoya a los discursos orientados no al entendimiento, sino a la confrontación.

\section{Conclusiones}

Hemos examinado la teoría populista desde un doble punto de vista, desde la crítica de Platón a la democracia y desde la crítica de Kant a la razón dogmática. Desde el primero, lo que encontramos el develamiento de la carencia de un necesario nivel cognitivista que tiene como implicancias la conducción a la democracia populista a la tiranía. La crítica de Kant a la razón dogmática muestra la manera en la que la apelación populista al «pueblo puro» supone una metafísica acrítica que cuestionada desde los recursos de la razón práctica ${ }^{2}$. Así, frente a dicha metafísica del pueblo se coloca la idea del pueblo, de la que no se tiene conocimiento especulativo, sino que sirve como elemento regulativo para la práctica del intercambio de razones.

La idea del pueblo no es otra que la del Reino de los fines (GMS, AA, 04: 433 ss), en el que agentes racionales, plurales, finitos y vulnerables se dan razones

2 Ciertamente, la crítica de Kant a la metafísica populista también le da a la presentada por Platón, pero esa es otra cuestión. 
mutuamente para perfilar los principios para la acción moral y política ${ }^{3}$. Esto revela el déficit normativo y cognitivista de la teoría cognitivistas, ya deriva la normatividad del mandato de la autoridad del líder populista, recurriendo a una estrategia voluntarista (Korsgaard, 2000, p. 32). Estos impases «teóricos» tienen sus consecuencias en el terreno de la acción política, ya que el populismo parece tener más éxito para los partidos de oposición que para los partidos de gobierno, y que parece tener ideas más cuajadas como intento de poder constituyente que como poder constituido. Pero debo subrayar el carácter hipotético del término «parece» porque con los déficits señalados el populismo parece que no logra objetivo alguno con éxito ni en el terreno de la teoría ni en el de la acción.

\section{REFERENCIAS BIBLIOGRÁFICAS}

Arato, A. (2013). Political Theology and Populism. Social Research, 80, 143-172.

Brandom, R. (2005). Hacerlo explícito. Razonamiento, representación y compromiso discursivo. Herder. Original publicado en 1994.

Cas, M. (2017). Populism. An Ideaciational Appoach. En The Oxford Handbook of Populism. Oxford University Press (pp. 46-70).

Cas, M., E Rovira Kaltwasser, C. (2019). Populismo. Una breve introducción. Alianza editorial. Original publicado en 2017.

Forst, R. (2014). Justificación y crítica. Perspectivas de una teoría crítica de la justicia. Katz.
Habermas, J. (2009). La lógica de las ciencias sociales. Tecnos. Original publicado en 1982.

Kant, I. (2009). Crítica de la razón pura. UNAM/FCE. Original publicado en 1781 (primera edición) y en 1787 (segunda edición).

Kant, I. (2018). Fundamentación para una metafísica de las costumbres. Alianza Editorial.

Korsgaard, C. (2000). Las fuentes de la normatividad. UNAM. Original publicado en 1996.

Laclau, E. (2020). La razón populista. FCE. Original publicado el 2005.

Platón. (2001). La república. Alianza Editorial.

Rovira Kaltwasser, C. (2019). El populismo en el siglo XXI. Punto y Coma, 25-31.

Sancho-Rocher, L. (2001). Democracia, saber y multitud. Platón y el demos. Polis, 13, 99-128.

Schmitt, C. (2003). La dictadura desde los comienzos del pensamiento moderno de la soberanía hasta la lucha de clases proletaria. Alianza Editorial. Original publicado en 1921.

Schmitt, C. (2004a). El concepto de lo "político." En H. O. Aguilar (Ed.), Carl Schmitt, teólogo de la política (pp. 167-223). FCE. Original publicado en 1939.

3 La distinción entre el Reino de los fines y el «pueblo puro» populista promete ser fructífera, pero su abordaje va más allá de los objetivos del presente trabajo. 
Schmitt, C. (2004b). Teología política I. Cuatro capítulos sobre la teoría de la soberanía. En H. O. Aguilar (Ed.), Carl Schmitt, teólogo de la política (pp. 19-62). FCE. Original publicado en 1922.
Weber, M. (2011). La ética protestante y el espíritu del capitalismo. FCE. Original publicado en 1920.

Fecha de recepción: 03/04/2021

Fecha de aceptación: 14/05/2021 
